\title{
ARICESA as an Alternative Learning Model to Improve Learning Motivation and Understanding of Student Concepts
}

\author{
Rahyu Setiani
}

STKIP PGRI Tulungagung, Postgraduate of Surabaya State University, Indonesia, rahyu@stkippgritulungagung.ac.id

I Gusti Made Sanjaya

State University of Surabaya, Indonesia, igmasanjaya@unesa.ac.id

Budi Jatmiko

State University of Surabaya, Indonesia, budijatmiko@unesa.ac.id

The ARICESA model was designed to improve learning motivation and understanding of student concepts. This study aims to develop a valid, practical, and effective ARICESA model to improve learning motivation and conceptual understanding of science teacher pre-service elementary school. The model was developed using the Plomp design with a preliminary study, prototyping, and assessment stages. The trial subjects were 34 students who programmed the Basic Concept of Elementary Science course. The trial was conducted using one-group pre-test and post-test design. A descriptive statistical analysis was used to determine the validity and practicality of the model, as well as inferential statistical analysis to determine the effectiveness of the learning model. The results showed that the ARICESA model: 1) was valid based on review of content and construct validity, and supported by valid learning materials, 2) practically used in learning as shown by excellent lecturer and student activities, 3) effective in improving the learning motivation by means of $\mathrm{N}$-gain .65 and improving the conceptual understanding by means of N-gain .72 to .76 for each topic. The implementation of the ARICESA model needs to be expanded for greater support of the practicality and effectiveness.

Keywords: ARICESA learning model, learning motivation, understanding of concepts

\section{INTRODUCTION}

In this era of globalization within the $21^{\text {st }}$-century, pre-service teachers are required to have excellence competencies with a variety of $21^{\text {st }}$-century skills (Urbani et al., 2017). Assessment and Teaching of $21^{\text {st }}$-Century Skills (ATC21S) categorize $21^{\text {st }}$-century skills 
into four categories, one of which is ways of thinking (Griffin, et al., 2012). The ways of thinking category consist of creativity, innovation, critical thinking, and metacognition (Patricia, e al., 2012). Motivation and confidence to succeed become the principle to achieve the ways of thinking category (Griffin et al., 2012). Understanding the concepts is also a principle to reach the level of ways of thinking category (Chu, et al., 2017). Creativity can improve if students have good learning motivation because learning motivation is the main factor for creative thinking (Hamza \& Hassan, 2016). The development of critical thinking skills and analytical thinking skills have to be driven by learning motivation (Miele \& Wigfield, 2014) while conceptual understandings are the initial stage for analytical thinking (Irwanto, et al., 2017). That is, to achieve $21^{\text {st }}$ century skills, pre-service teachers must improve the learning motivation and understanding the concepts in learning.

Students at the higher education level said that they were not motivated in the learning environment (Cetin-dindar, 2015; Ng, et al., 2016). These conditions become an inhibiting factor in optimizing the understanding of the concepts (Andersen \& Cross, 2014). Students tend to have planning and management of science learning tasks (choice of tasks) in the low category (Plenty \& Heubeck, 2013). Meanwhile, students' anxiety intake on science tests and receiving test results are at a very high level (de Silva, et al., 2017). This indicates that students feel anxious or lack self-confidence in science learning. Students have a low level of literacy in science learning activities and also a low level of using the time for learning (persistence) (Woods-McConney, et al., 2013). Each of the choices of tasks, effort, persistence, and self-confidence are indicators of learning motivation which are the principles for improving the learning achievement. (Ng et al., 2016).

\section{LITERATURE REVIEW}

The expectancy-value theory explained that motivation was formed from two main forces: the individual's expectation of reaching a goal and the individual's value of that goal (Woolfolk, 2016). Based on the studies related to expectancy-value theory, motivation can be viewed from the choices, persistence, and actions of a person while learning (Wigfield \& Eccles, 2000). Students indicate motivation through their interest in doing assignments (choice of tasks), trying optimally in the process (effort), and spending a lot of time (persistence) to perform these activities (Schunk, 2012). Motivation to perform activities is the desire to meet the needs of self-development (achievement motive) (Schunk, 2012). Students who are motivated, will not feel worried when they have to take on various kinds of tests given because they have the confidence to succeed (self-confidence) (Woolfolk, 2016). Learning motivation can be measured based on five indicators that are the choice of task, effort, persistence, self-confidence, and achievement.

The main idea of education is learning that afford students an understanding of concepts (Konicek-Moran \& Keeley, 2015). The concept is an abstraction that can help a person construct comprehensive thinking as a tool to organize views and predict an action along with its classification (Konicek-Moran \& Keeley, 2015). Based on Bloom's revised taxonomy, the understanding was categorized into seven that is (1) interpreting; (2) 
exemplifying; (3) classifying; (4) summarizing; (5) inferring; (6) comparing; and (7) explaining (Anderson et al., 2001). All of the understanding categories can be achieved by the inquiry model that give chance for students to learn how to find the facts and concepts through direct experience (Putra, Widodo, \& Jatmiko, 2016). The inquiry model can improve the understanding of concepts and have a positive impact on learning motivation (Nisa, et al., 2018; Trnova \& Trna, 2015), even though not significantly (Wang, et al., 2015). The inquiry model implementation requires students who are motivated to learn (Capps \& Crawford, 2013; Meyer, et al., 2013).

Learning that does not provide strategies to motivate students, makes understanding of concepts hard to achieve (Bernardo, et al., 2015). Presenting narratives to motivate scientific problem solving is very efficient for improving motivation and understanding of concepts in science learning (Trnova \& Trna, 2015). The learning strategies implementation needs to present the science context in daily phenomena, approaches of scientific interdisciplinary, and strategies to improve learning motivation (Santrock, 2018; Serafin, 2016). An orientation of learning objectives both mastery of concepts and processes must be conveyed by the lecturer so that students can be more motivated (Patrick \& Yoon, 2004).

Science learning need forms self-confidence till students can eliminate their anxiety (de Silva et al., 2017). ARCS (Attention, Relevance, Confidence, Satisfaction) is a motivational model designed by Keller to improve students' motivation and confidence in learning (Huett, et al., 2008) and be able to provide support for various kinds of learning (Huang \& Hew, 2016; Jachin \& Usagawa, 2017). The ARCS model enables students to quickly gain an overview of the major dimensions of learning motivation, and how to create strategies to stimulate and sustain motivation in each of the four areas (Keller, 2010). Student motivation can be stimulated using a strategy that captures attention, presents relevance of the learning matter to their needs, provides a stimulus of confidence to succeed and a sense of satisfaction towards their performance results (Keller, 2010).

Based on the Csikszentmihalyi's flow theory there are three main factors that represent the state of students flowing in learning are interest, concentration, and enjoyment (Keller, 2010). The attention phase in ARCS model is certainly capable of arousing student interest and concentration (Shernoff, et al., 2003). Learning must conform to flow theory, which can make someone who is learning feel comfortable performing the activity (Rodríguez-Ardura \& Meseguer-Artola, 2017). The learning process will continuously develop when students feel enthusiastic about being involved in learning, enjoying challenges, and maintaining a successful perspective (Hayes, 2007). Selfassessment contributes to metacognitive skills related to achievement as an indicator of learning success (Brown \& Harris, 2014). Self-assessment is a manifestation of student involvement in identifying standards and/or criteria to be applied to their work and making judgments about the extent to which they have met these criteria and standards (Boud, 1995). The results of self-assessment provide support for satisfaction in the ARCS model (Orji, et al., 2018). Self-assessment is a skill that needs to be developed to support students promoting themselves (Panadero, et al., 2018). The inquiry and ARCS 
models have been integrated by combining a component of enjoyment learning to create an environment of fun and self-assessment as an appraisal system that does not cause anxiety and despair of learning outcomes. A new learning model has formed, called ARICESA (Attention, Relevance, Inquiry, Confidence, Enjoyment, Satisfaction, and self-Assessment) to improve learning motivation and understanding the basic concepts of elementary science.

\section{Research Question}

This study aims to develop a valid, practical and effective ARICESA model supported by its learning materials. The research questions of the study are:

(1) How is the ARICESA model validity for improving the learning motivation and understanding of the concepts?

(2) How is the ARICESA model practicality when implementing in a trial class?

(3) How is the ARICESA model effectiveness for improving the learning motivation and conceptual understanding?

\section{METHOD}

This study aims to develop a valid, practical and effective ARICESA learning model so that it can improve learning motivation and understanding of the basic concepts of science for pre-service elementary teacher. The ARICESA model stated to be valid if the assessment results of the component of content and construct validity, and supporting materials of the ARICESA model, are minimally valid and reliable category; it was stated to be practical if the observation results of the model practicality and student activities are minimally in good category; and it was stated to be effective when the mean of normalized gain (N-gain) for learning motivation and understanding of concepts, are minimally in medium category with a significant improvement based on inferential statistical test results.

Learning materials to support ARICESA model implementation include the Lecturer Unit, Student Worksheet, and Learning Book. The development design consists of three steps, a preliminary study, prototyping, and assessment stage (Plomp \& Nieveen, 2013). The model design has actualized in the form of the ARICESA Model Book which was validated by experts through a Focus Group Discussion (FGD) on the prototyping stage. The model validity was determined based on the components of content and construct validity. Furthermore, a limited trial was directed with the implementation of the ARICESA model in one class to obtain a prototype learning model with the following characteristics: (1) the validity of models and supporting materials for model implementation; (2) the practicality of the model which includes the lecturer and student activities, and the obstacles met; (3) the effectiveness of the model to improve learning motivation and understanding of basic concepts of Elementary Science on the preservice elementary teacher.

\section{Participants}

The validity assessment of the ARICESA model and the learning materials through the FGD involved three education experts. Each of them has expertise in developing 
learning models, developing learning materials, and elementary science learning. The limited trial of the ARICESA model has directed on 34 pre-service elementary teachers. The sample in this study was $2^{\text {nd }}$-grade students who were programming the Basic Concept of Elementary Science course. A model lecturer was also involved in a limited trial to implement learning and was accompanied by two observers.

\section{Instrument and Procedures}

The assessment sheets of content and construct validity were used as instruments to determine the validity of the ARICESA model. The ARICESA-based learning materials were assessed for its validity using the Validity Assessment Sheet, in particular: Lecturer Units, Student Worksheets, and Learning Book. Learning materials including several topics are particularly: Forces and Motion in Life, Energy and Change, Temperature Measurement, Heat and Transfer, Sound Waves, and Light Waves. The practicality of the ARICESA model was determined based on learning observations using observation sheets of lecturer and student activities. Measurement of learning motivation and understanding of elementary science concepts was carried out before and after the implementation of the ARICESA model in Basic Concept of Elementary Science course. Learning motivation was measured by the learning motivation questionnaire, while understanding of concept was measured by the conceptual test of elementary science for each topic. The test was in essay form by an allocation time of 120 minutes.

The learning motivation questionnaire and conceptual test instrument used in this study had been developed by the researcher. Those instruments had been validated empirically and theoretically by three experts in the fields of education and science. The evaluation aspects were construction, materials, language, and time allocation of the instrument. The validation results had confirmed that the learning motivation questionnaire scores 9.11 (with a score range 1-10) in a very valid category and the reliability coefficient had calculated as .89 in the strong reliability category, which consists of 42 statements. The conceptual test instrument consisted of 7 questions for each topic that have a validity scores 8.89 in a very valid category with the reliability coefficient was calculated as .81 in the strong reliability category.

\section{Data Analysis}

A quantitative descriptive analysis was used to determine the validity of the model and learning materials, and learning model practicality. Three experts as validators of the ARICESA model provide a value with a range of 1-10 in the validity assessment instrument and then determine the average value of each component and determine its reliability. The practicality of each phase learning and student activities were observed and assessed by giving a score of 4 (Very Good), 3 (Good), 2 (Poor), 1 (Very Poor). The results of validations and observations were determined by the mean score of each component and its reliability from inter raters agreement for ordinal data. The reliability was determined using the Intraclass Correlation Coefficients (ICC) equation:

$$
I C C=\frac{M S_{R}-M S_{E}}{M S_{R}}
$$


where $\mathrm{MS}_{\mathrm{R}}=$ mean square for rows and $\mathrm{MS}_{\mathrm{E}}=$ mean square for error. The value of ICC was used to evaluate the level of reliability using the following general guideline: ICC < .50 (poor reliability); $.50<$ ICC $<.75$ (moderate reliability); $.75<$ ICC $<.90$ (good reliability), and ICC > .90 (excellent reliability) (Koo \& Li, 2016).

Data about learning motivation and understanding of concept were analyzed using descriptive statistics and inferential statistics to determine the significance of increased learning motivation. Student learning motivation was described based on each indicator, particularly Choice of Tasks, Effort, Persistence, Self-Confidence, and Achievement. The improvement of learning motivation was tested by Wilcoxon Signed Rank in an ordinal scale. The improving significance of understanding the Basic Science of Elementary Science was analyzed by paired t-test because in a ratio scale and it had filled the assumption of data normality. The normality of conceptual understanding scores was tested using Kolmogorov-Smirnov on each topic. The mean of normalized gain (N-gain) was used to determine the improvement level in learning motivation and understanding of the elementary science concepts between before and after learning. Hake $(1999)$ stated, N-gain $=($ post-test score - pre-test score $) /($ maximum score - pretest score), with criteria: $\mathrm{N}$-gain $>.70$ (high); . $30<\mathrm{N}$-gain < .70 (medium); dan $\mathrm{N}$-gain $<.30$ (low).

\section{FINDINGS}

\section{Content Validity of ARICESA Learning Model}

The assessment results of the ARICESA model's content validity are presented briefly in Table 1 . The content validity gets very valid criteria in terms of the model development needs to support $21^{\text {st }}$-century skills, support the national qualification framework according to the higher education standard in Indonesia, fit the gap between the expectations and realities of current learning (especially the low learning motivation and understanding of concepts), and appropriate on suggestions for innovative learning improvement (ARCS and Inquiry models). Each of assessment aspect of the ARICESA model development needs has reached the validity criteria.

Table 1

The Assessment Results of ARICESA Model in Terms of Content Validity

\begin{tabular}{lllll}
\hline \multicolumn{1}{c}{ Component of Content Validity } & Mean & Criteria & ICC & Level of Reliability \\
\hline $\begin{array}{l}\text { Model development needs } \\
\begin{array}{l}\text { Latest knowledge support of model } \\
\text { development }\end{array}\end{array}$ & 8.47 & Very Valid & .53 & Moderate \\
\hline
\end{tabular}

The content validity gets very valid criteria in terms of the latest knowledge support in the development of model objectives, theoretical and empirical framework, a rise of the learning design and preparation, learning environment, learning assessment, and efforts to promote further research. The intraclass correlation coefficient of each content validity aspects are .53 and .64 in the level of moderate reliability. 


\section{Construct Validity of ARICESA Model}

Table 2 presents the construct validity about the internal components of the ARICESA model involving learning objectives and results (9.00), theoretical and empirical framework (8.56), syntax or learning phases (8.83), and learning environment management (8.67). Each mean score of the validator and its reliability is 8.71 and $95.22 \%$. This confirms that learning model fills construct validity.

Table 2

The Assessment Results of ARICESA Model in Terms of Construct Validity

\begin{tabular}{lllll}
\hline \multicolumn{1}{c}{ Component of Construct Validity } & Mean & Criteria & ICC & Level of Reliability \\
\hline Learning objectives & 9.00 & Very Valid & .51 & Moderate \\
Theoretical and empirical framework & 8.56 & Very Valid & .62 & Moderate \\
Learning syntax & 8.83 & Very Valid & .51 & Moderate \\
Learning environment management & 8.67 & Very Valid & .73 & Moderate \\
\hline
\end{tabular}

\section{The Validity of ARICESA-Based Learning Materials}

The validity assessment of the lecturer units was categorized into two kinds, about the completeness of the lecture unit components and the learning syntax. The assessment results of lecture unit validity are presented in Table 3, which generally gets in very valid criteria. The validators suggest for adjusting the time allocation with the learning objectives, attention phase activities are described by the parts of specific methods and media, and then explain the self-assessment clearly.

Table 3 presents the lecture unit validity with each component scores are the component completeness of 8.52 and the learning syntax of 8.47. The assessment results of the learning book validity include contents propriety (9.22), presentation structure (9.10), language structure (9.07), and graphics design (9.13). Each component of the learning book validity has a score of more than 9 with an overall mean of 9.13 , which indicates the validator state that the learning book is very valid. The assessment results of the student worksheets for each component are didactic of 8.75 , contents structure of 8.58 , presentation structure of 8.83 , and time allocation of 8.00 .

Table 3

The Assessment Results of Lecturer Units, Learning Book, and Student Worksheets

\begin{tabular}{lllll}
\hline Learning Materials & \multicolumn{1}{c}{ Components of Validity } & Score & ICC & Level of Reliability \\
\hline \multirow{2}{*}{ Lecturer Units } & Completeness of Components & 8.52 & .51 & Moderate \\
& Learning Syntax & 8.47 & .63 & Moderate \\
& Contents & 9.22 & .58 & Moderate \\
\multirow{5}{*}{ Learning Book } & Presentation Structure & 9.10 & .69 & Moderate \\
& Language Structure & 9.07 & .65 & Moderate \\
& Graphic design & 9.13 & .67 & Moderate \\
& Didactic & 8.75 & .71 & Moderate \\
\multirow{5}{*}{ Student Worksheets } & Contents & 8.58 & .60 & Moderate \\
& Presentation Structure & 8.83 & .67 & Moderate \\
& Time Allocation & 8.00 & .51 & Moderate \\
\hline
\end{tabular}




\section{Lecturer and Student Activities in the Implementation of ARICESA Model}

Lecturers perform the ARICESA-based learning was accompanied by two observers. Learning was performed based on lecturer units in six courses. The observations results of lecturer unit's practicality are presented briefly in Table 4. The practicality of the ARICESA model phases in all courses was very good with a mean score of 3.63 or with a practicality percentage of $90.85 \%$. The observing of student activities was aligned with the phases of learning that have planned in lecturer units. Student activities that relevant to the ARICESA model improve at each course. The mean score of the observations within the entire course was 3.55 with a percentage of student activity of $88.72 \%$. Overall, these results indicate that students can follow all phases of the ARICESA model well.

Table 4

The Observation Results of Lecturer and Student Activities

\begin{tabular}{|c|c|c|c|c|c|c|c|c|c|c|c|c|}
\hline \multirow{2}{*}{ Phase of the Model } & \multicolumn{6}{|c|}{ Scores of Lecturer Performance } & \multicolumn{6}{|c|}{ Scores of Student Activity } \\
\hline & 1 & 2 & 3 & 4 & 5 & 6 & 1 & 2 & 3 & 4 & 5 & 6 \\
\hline Attention & 3.83 & 3.67 & 3.67 & 3.67 & 3.33 & 3.67 & 3.33 & 3.67 & 3.67 & 3.83 & 3.83 & 4.00 \\
\hline Relevance & 4.00 & 3.50 & 3.50 & 3.50 & 3.67 & 3.67 & 3.00 & 3.00 & 3.50 & 4.00 & 3.50 & 4.00 \\
\hline Inquiry & 3.63 & 3.25 & 3.38 & 3.38 & 3.63 & 3.63 & 3.13 & 3.25 & 3.75 & 3.63 & 3.75 & 3.88 \\
\hline Confidence & 3.83 & 3.50 & 3.67 & 3.67 & 3.50 & 3.50 & 3.00 & 3.17 & 3.50 & 3.83 & 3.83 & 3.83 \\
\hline Enjoyment & 3.83 & 3.83 & 3.83 & 3.83 & 3.67 & 3.67 & 3.00 & 3.17 & 3.17 & 3.83 & 3.67 & 3.83 \\
\hline Satisfaction & 3.83 & 3.83 & 3.50 & 3.50 & 3.67 & 3.67 & 3.00 & 3.00 & 3.67 & 3.83 & 3.83 & 3.83 \\
\hline Self-Assessment & 3.83 & 3.83 & 3.83 & 3.83 & 3.67 & 3.67 & 3.00 & 3.33 & 3.50 & 3.83 & 3.83 & 3.83 \\
\hline Reliability (ICC) & .96 & .94 & .95 & .95 & .96 & .96 & .98 & .96 & .95 & .94 & .96 & .97 \\
\hline Practicality & \multicolumn{6}{|c|}{$90,85 \%$ (Very Good) } & \multicolumn{6}{|c|}{$88,72 \%$ (Very Good) } \\
\hline
\end{tabular}

\section{Learning Motivation}

The mean of earlier and end motivation are 1.91 and 3.92, respectively. The median of learning motivation shifted from 1.89 for the earlier motivation to 3.89 for the end motivation. The mode of learning motivation is 1.55 for the earlier motivation and 3.81 for the end motivation. Table 5 presents that the implementation of the ARICESA model can improve the mean score of learning motivation on each indicator. The measurement results of earlier and end motivation indicate an improvement with a mean of $\mathrm{N}$-gain of .65 in the medium level.

Table 5

The Assessment Results of Earlier Motivation and End Motivation Scores

\begin{tabular}{lllcl}
\hline Motivation Indicators & Earlier Motivation & End Motivation & N-gain & Level \\
\hline Choice of Tasks & 1.92 & 3.95 & .66 & Medium \\
Effort & 1.86 & 3.94 & .66 & Medium \\
Persistence & 1.89 & 3.88 & .64 & Medium \\
Self-Confidence & 1.97 & 3.96 & .66 & Medium \\
Achievement & 1.89 & 3.83 & .62 & Medium \\
Mean & 1.91 & 3.91 & .65 & Medium \\
\hline
\end{tabular}


The results of the Wilcoxon Signed Rank test on learning motivation are presented in Table 6. The positive rank value of the Wilcoxon Signed Rank Statistic test is 34, which confirms that all students have an improvement in learning motivation. Test results also have a p-value (significance) $<.0001(<.05)$, resulting in rejection of $\mathrm{H}_{0}$. This proposes that the motivation of pre-service elementary teacher differs significantly between before and after learning science by the ARICESA model in a limited trial class.

Table 6

N-gain and Wilcoxon Signed Rank Statistic Test of Learning Motivation

\begin{tabular}{lllll}
\hline \multirow{2}{*}{$\begin{array}{l}\text { Mean of } \\
\text { N-gain }\end{array}$} & \multirow{2}{*}{ Criteria } & \multicolumn{3}{l}{ Result of Wilcoxon Signed Rank Statistic Test } \\
\cline { 3 - 5 } & & Negative Rank & Positive Rank & $p$ \\
\hline .65 & Medium & 0 & 34 & $<.0001^{*}$ \\
\hline$* p<.05$ & & &
\end{tabular}

\section{The Understanding of Basic Concept of Elementary Science}

Table 8 presents that the implementation of the ARICESA model can improve the understanding of Basic Concept of Elementary Science on each topic. This is indicated by the mean of $\mathrm{N}$-gain with high level. To obtain the significance of the conceptual understanding improvement, it needs to test the similarity using paired t-tests. This test had performed because the gain score of understanding the concept meets normality with p-value was more than .05 on each topic as shown in Table 7 . The p-value of paired t-test for the pre-test and post-test on each topic was less than .05 . Thus, $\mathrm{H}_{0}$ is rejected with the implication that there is a significant difference between understanding the Basic Concept of Elementary Science on Pre-service elementary teacher from the pre-test and post-test results through each topic. The overall $t$ shows a negative value which indicates that the mean of pre-test value is smaller than the post-test or an improvement in the value of understanding of Basic Concept of Elementary Science on Pre-service elementary teacher between before and after learning with the ARICESA model.

Table 7

Normality Test of the Understanding of Concept using the Kolmogorov-Smirnov Test

\begin{tabular}{llll}
\hline \multicolumn{1}{c}{ Topics } & Statistic & df & $p$ \\
\hline Force and Motion & .074 & 34 & $.200^{*}$ \\
Energy and Its Change & .120 & 34 & $.200^{*}$ \\
Temperature & .086 & 34 & $.200^{*}$ \\
Heat and Transfer & .118 & 34 & $.200^{*}$ \\
Sound Wave & .129 & 34 & $.166^{*}$ \\
Light Wave & .120 & 34 & $.200^{*}$ \\
\hline
\end{tabular}

$* p>.05$ 
Table 8

$\mathrm{N}$-gain and Paired T-Test of the Understanding of the Concepts

\begin{tabular}{|c|c|c|c|c|c|c|c|}
\hline \multirow{2}{*}{ Topics } & \multirow{2}{*}{$\mathrm{x}_{\mathrm{i}}$} & \multirow{2}{*}{$x_{f}$} & \multirow{2}{*}{$\mathrm{N}$-gain } & \multirow{2}{*}{ Level } & \multicolumn{3}{|c|}{ Result of Paired T-Test } \\
\hline & & & & & $\Delta \mathrm{x}$ & $\mathrm{t}$ & $p$ \\
\hline Force and Motion & 17.53 & 78.88 & .74 & High & -61.353 & -29.819 & $<.0001 *$ \\
\hline Energy and Its Change & 15.65 & 76.59 & .72 & High & -60.941 & -26.873 & $<.0001 *$ \\
\hline Temperature & 16.41 & 80.53 & .77 & High & -64.118 & -29.337 & $<.0001 *$ \\
\hline Heat and Transfer & 17.65 & 79.76 & .75 & High & -62.118 & -33.033 & $<.0001 *$ \\
\hline Sound Wave & 17.94 & 80.18 & .76 & High & -62.235 & -29.702 & $<.0001 *$ \\
\hline Light Wave & 19.59 & 81.06 & .76 & High & -61.471 & -33.968 & $<.0001 *$ \\
\hline
\end{tabular}

\section{DISCUSSION}

The development of the ARICESA model was carried out through modification of the ARCS model by combining external motivation factors. The ARCS model was developed as a motivational model that focuses on individuals as a source of motivation, so that the categories of attention, relevance, confidence, and satisfaction need to be reached from the individual's internal and be promoted by lecturers. The ARICESA model presents more systematic external factors through fun learning conditions that are the environment, the substance of learning, and psychological and social conditions. The intervention carried out in the ARCS model is in the form of the principle of active student involvement in the Inquiry model, the pleasant of atmosphere and learning environment at Joyful (Enjoyment) Learning, and the seeding of personal control optimism in Self-Assessment. The results of these interventions were able to improve learning motivation, both from internal and external factors (Table 5). Interventions with the Inquiry model and the self-assessment principle have an impact on cognitive and metacognition reinforcement by the results of improved understanding of concepts (Table 8).

Lecturers must be able to attract attention or make students focus on starting learning by arousing learning passion through varied and innovative methods in phase A (Attention). In this phase, it is necessary to explore students' initial knowledge of a material (phenomenon or earlier problem). Students respond by expressing their opinions or earlier knowledge of learning topic (phenomenon or earlier problem). Student activity in phase A proved to improve to be more focused when starting learning (Table 4). Phase $\mathrm{R}$ (Relevance) aims to present the relevance of the matter to the principle of familiarity (suitability in the context of everyday life). Lecturers must be able to present the orientation of the learning objectives of a matter. Thus, students understand the relevance of the matter to the context of life and learning objectives. Knowledge of the relevance of the concept with phenomena or activities in life becomes the base of knowledge in order to involve the benefits of science, especially in life (Woods-McConney et al., 2013). 
Phase I (Inquiry) can support the understanding of the Basic Concept of Elementary Science through activities based on scientific procedures. With the guidance of lecturers, students have been able to plan an experiment, observe, interpret, and analyze the data that has been collected to make conclusions. Students have an improved understanding of concepts after model implementation (Table 8). The findings of previous studies have also proven that inquiry can improve understanding of concepts (Bartel \& Hagel, 2014; Lee, et al., 2018; Roll et al., 2018) Phase C (Confidence) and A (self-assessment) support the achievement of student competencies regarding responsibility for their performance. Lecturers must be able to stimulate self-confidence in students by explaining the importance of confidence in a performance during phase $\mathrm{C}$ (Confidence). Lecturers must arouse students' confidence to succeed in learning by introducing personal control so that they can arouse their self-confidence and belief in success. Most of the significant effects of self-assessment are that students can be personally responsible for the improvement of their competencies (Panadero, et al., 2017). Studentcentered learning by actively involving them in the scientific process and assigning tasks or challenges will be able to shift the responsibilities which initially from external factors into internal factors (kesadaran pribadi) (Breunig, 2017).

Phase E (Enjoyment) and S (Satisfaction) become interventions to make students flow in the whole of learning with feeling comfortable and full of joy. Lecturers must be able to create a learning environment, compile the substance of fun learning and make students comfortable. Psychological connections must be built through personal and social communication strategies in the classroom to make students dissolve and flow in a series of learning with a comfortable and enjoyable atmosphere (Lemley, et al., 2014). The environment and learning atmosphere affect the comfort in establishing communication between lecturers and students (Wang et al., 2015). Awards must be given to students as extrinsic rewards to their performance and direct students to enjoy their learning experiences. Students who feel valued will be more motivated to learning continuously (Keller, 2010; Tlili, et al., 2017).

The ARICESA model has been designed logically and consistently as a construct validity criterion, which has a theoretical framework and previous research suggestions, especially regarding the weaknesses of the ARCS and Inquiry models. Based on content validity, the ARICESA model is relevant to $21^{\text {st }}$-century student skills needs. The ARCS motivation model can return the challenge of motivational problems in learning during developing $21^{\text {st }}$-century skills. The inquiry model which is the phase of the ARICESA model can be a solution to $21^{\text {st }}$-century learning needs. Three dimensions of $21^{\text {st }}$-century learning have been created in the ARICESA model, which is information, communication, and social ethics and control. The most important thing for students in promoting $21^{\text {st }}$-century skills is the communication relationship with lecturers. Phase $\mathrm{E}$ (Enjoyment) is the solution to communication needs and a comfortable learning atmosphere. ARICESA-based learning has been able to involve students in full, including in the assessment process in phase A (self-assessment).

The novelty of the ARICESA model lies in the syntax used, namely: (1) in the phase (A) Attention, the lecturer must be able to attract attention or make students focus to begin 
learning with interactive communication about the initial knowledge of learning matter (phenomena/earlier problems); (2) in the R (Relevance) phase, students are invited to understand the relevance of the matter to the context of life and learning objectives; (3) in Phase I (Inquiry), students are required to be actively involved in the process of hypothesis formulation, data collection, data management, and formulation of results, as well as given time to work in groups; (4) in phase C (Confidence), students are given a stimulus to apply a personal control system to arouse their confidence and belief in success; (5) in phase E (Enjoyment), the lecturer must create a learning environment, form the matter of enjoyment learning and make students comfortable by establishing a psychological relationship through personal and social communication strategies in the classroom to make students dissolve and flow in the learning with an enjoyable atmosphere; (6) in the $\mathrm{S}$ phase (Satisfaction), the lecturer must be able to give awards to students as extrinsic rewards to their performance and direct students to make their learning experience a pleasure; (7) in phase A (self-assessment), students are given guidance and chances to do self-assessments related to the results achieved in learning.

\section{CONCLUSION}

The ARICESA model has filled the contents and constructs validity, and has supported by lecturer units, learning book and student worksheets that are valid. The practicality of the model based on the lecturer's performance and student activities at each course has a very good category. This confirms that the ARICESA model is practical to use in learning. The ARICESA model can improve learning motivation at the medium level, and improve understanding of Basic Concept of Elementary Science at the high level, which is indicated by the $\mathrm{N}$-gain value. Further research is expected to achieve a high level of $\mathrm{N}$-gain in learning motivation. The implementation of the ARICESA model needs to be expanded for greater support of the practicality and effectiveness.

\section{LIMITATIONS}

First, our study presents the results of ARICESA model implementation in the limited trial samples. These samples still need to be added more to generalize the results. A consistency test of the model implementation in an expanded scope needs to be done to provide support in generalizing the results. Secondly, our research is still limited to six topics: Forces and Motion in Life, Energy and Change, Temperature Measurement, Heat and Transfer, Sound Waves, and Light Waves. Basic Concept of Elementary Science still has any interesting topics to teach with the ARICESA model. The implementation of the ARICESA model will provide comparative data on the results of learning motivation and conceptual understanding.

\section{ACKNOWLEDEMENTS}

This study was supported by the Ministry of Research, Technology, and Higher Education of the Republic of Indonesia, State University of Surabaya, and STKIP PGRI Tulungagung.

\section{REFERENCES}

Andersen, L., \& Cross, T. L. (2014). Are Students With High Ability in Math More 
Motivated in Math and Science Than Other Students? Roeper Review, 36(4), 221-234. https://doi.org/10.1080/02783193.2014.945221

Anderson, L. W., Krathwohl, D. R., Airasian, P. W., Cruikshank, K. A., Mayer, R. E., Pintrich, P. R., ... Wittrock, M. C. (2001). A Taxonomy for Learning, Teaching, and Assessing: A Revision of Bloom's Taxonomy of Educational Objectives. United. States: Pearson Education. Inc.

Bartel, A., \& Hagel, G. (2014). Engaging students with a mobile game-based learning system in university education. 2014 4th IEEE Global Engineering Education Conference: Engineering Education Towards Openness and Sustainability, IEEE EDUCON 2014, 957-960. https://doi.org/10.1109/EDUCON.2014.6826215

Bernardo, A. B. I., Ganotice, F. A., \& King, R. B. (2015). Motivation Gap and Achievement Gap Between Public and Private High Schools in the Philippines. AsiaPacific Education Researcher, 24(4), 657-667. https://doi.org/10.1007/s40299-0140213-2

Boud, D. (1995). Enhancing learning through self assessment. New York: RoutledgeFalmer.

Breunig, M. (2017). Experientially learning and teaching in a student- directed classroom. Journal of Experiential Education, 40(3), 213-230. https://doi.org/10.1177/1053825917690870

Brown, G., \& Harris, L. (2014). The future of self-assessment in classroom practice: Reframing self- assessment as a core competency. Frontline Learning Research, 3, 22 30. https://doi.org/10.14786/flr.v2i1.24

Capps, D. K., \& Crawford, B. A. (2013). Inquiry-Based Instruction and Teaching About Nature of Science: Are They Happening? Journal of Science Teacher Education, 24(3), 497-526. https://doi.org/10.1007/s10972-012-9314-z

Cetin-dindar, A. (2015). Student Motivation in Constructivist Learning Environment. EURASIA Journal of Mathematics, Science \& Technology Education, 12(2), 233-247. https://doi.org/10.12973/eurasia.2016.1399a

Chu, S. K. W., Reynolds, R. B., Tavares, N. J., Notari, M., \& Lee, C. W. Y. (2017). 21st Century Skills Development Through Inquiry-Based Learning. Singapore: Springer Science+Business Media. https://doi.org/10.1007/978-981-10-2481-8

de Silva, A. D. A., Khatibi, A., \& Ferdous Azam, S. M. (2017). Do the Demographic Differences Manifest in Motivation to Learn Science and Impact on Science Performance? Evidence from Sri Lanka. International Journal of Science and Mathematics Education, 1-21. https://doi.org/10.1007/s10763-017-9846-y

Griffin, P., Care, E., \& McGaw, B. (2012). The Changing Role of Education and Schools. In Assessment and Teaching of 21st Century Skills (pp. 1-15). Springer Science+Business Media. https://doi.org/10.1007/978-94-017-9395-7

Hamza, T. S., \& Hassan, D. K. (2016). Consequential creativity: Student competency and lateral thinking incorporation in architectural education. International Journal of Technology and Design Education, 26(4), 587-612. https://doi.org/10.1007/s10798- 


\section{5-9321-4}

Hayes, D. (2007). Joyful teaching and learning in the primary school. Southernhay East: Learning Matters Ltd. https://doi.org/10.4135/9781446278765

Huang, B., \& Hew, K. F. (2016). Measuring Learners' Motivation Level in Massive Open Online Courses. International Journal of Information and Education Technology, 6(10), 759-764. https://doi.org/10.7763/IJIET.2016.V6.788

Huett, J. B., Moller, L., Bray, M., Young, J., \& Huett, K. C. (2008). Supporting the Distant Student: The Effect of ARCS-Based Strategies on Confidence and Performance. Quarterly Review of Distance Education, 9(2), 113-126.

Irwanto, Rohaeti, E., Widjajanti, E., \& Suyanta. (2017). Students' science process skill and analytical thinking ability in chemistry learning. AIP Conference Proceedings, 1868. https://doi.org/10.1063/1.4995100

Jachin, N., \& Usagawa, T. (2017). Potential Impact of Blended Learning on Teacher Education in Mongolia. Creative Education, 08(09), 1481-1494. https://doi.org/10.4236/ce.2017.89104

Keller, J. M. (2010). Motivational Design for Learning and Performance: The ARCS Model Approach. New York: Springer Science and Business Media.

Konicek-Moran, R., \& Keeley, P. (2015). Teaching for Conceptual Understanding in Science. Arlington: National Science Teachers Association Press.

Koo, T. K., \& Li, M. Y. (2016). A Guideline of Selecting and Reporting Intraclass Correlation Coefficients for Reliability Research. Journal of Chiropractic Medicine, 15(2), 155-163. https://doi.org/10.1016/j.jcm.2016.02.012

Lee, Y. C., Lee, C. K. P., Lam, I. C. M., Kwok, P. W., \& So, W. W. M. (2018). Inquiry Science Learning and Teaching: a Comparison Between the Conceptions and Attitudes of Pre-service Elementary Teachers in Hong Kong and the United States. Research in Science Education, 1-25. https://doi.org/10.1007/s11165-017-9687-2

Lemley, J. B., Schumacher, G., \& Vesey, W. (2014). What Learning Environments Best Address 21st-Century Students' Perceived Needs at the Secondary Level of Instruction? NASSP Bulletin, 98(2), 101-125. https://doi.org/10.1177/0192636514528748

Meyer, D. Z., Antink Meyer, A., Nabb, K. A., Connell, M. G., \& Avery, L. M. (2013). A Theoretical and Empirical Exploration of Intrinsic Problems in Designing Inquiry Activities. Research in Science Education, 43(1), 57-76. https://doi.org/10.1007/s11165-011-9243-4

Miele, D. B., \& Wigfield, A. (2014). Quantitative and Qualitative Relations Between Motivation and Critical-Analytic Thinking. Educational Psychology Review, 26(4), 519-541. https://doi.org/10.1007/s10648-014-9282-2

Ng, B., Liu, W. C., \& Wang, J. C. K. (2016). Student Motivation and Learning in Mathematics and Science: A Cluster Analysis. International Journal of Science and Mathematics Education, 14(7), 1359-1376. https://doi.org/10.1007/s10763-015-9654-1

Nisa, E. K., Koestiari, T., Habibbulloh, M., \& Jatmiko, B. (2018). Effectiveness of 
guided inquiry learning model to improve students' critical thinking skills at senior high school. Journal of Physics: Conference Series, 997, 012049. https://doi.org/10.1088/1742-6596/997/1/012049

Orji, R., Reilly, D., Oyibo, K., \& Orji, F. A. (2018). Deconstructing persuasiveness of strategies in behaviour change systems using the ARCS model of motivation. Behaviour and Information Technology, 1-17. https://doi.org/10.1080/0144929X.2018.1520302

Panadero, E., \& Alonso-Tapia, J. (2013). Self-assessment: Theoretical and practical connotations. When it happens, how is it acquired and what to do to develop it in our students. Electronic Journal of Research in Educational Psychology, 11(2), 551-576. https://doi.org/10.14204/ejrep.30.12200

Panadero, E., Garcia, D., \& Fraile, J. (2018). Self-Assessment for Learning in Vocational Education and Training. In McGrath S., Mulder M., Papier J., Suart R. (eds) Handbook of Vocational Education and Training: Developments in the Changing World of Work (pp. 1-12). Springer, Cham.

Panadero, E., Jonsson, A., \& Botella, J. (2017). Effects of self-assessment on selfregulated learning and self-efficacy: Four meta-analyses. Educational Research Review, 22, 74-98. https://doi.org/10.1016/j.edurev.2017.08.004

Patricia A. Alexander, \& The Disciplined Reading and Learning Research Laboratory. (2012). Reading Into the Future: Competence for the 21st Century. Educational Psychologist, 47(4), 259-280. https://doi.org/10.1080/00461520.2012.722511

Patrick, H., \& Yoon, C. (2004). Early Adolescents' Motivation During Science Investigation. Journal of Educational Research, 97(6), 319-328. https://doi.org/10.3200/JOER.97.6.319-328

Plenty, S., \& Heubeck, B. G. (2013). A multidimensional analysis of changes in mathematics motivation and engagement during high school. Educational Psychology, 33(1), 14-30. https://doi.org/10.1080/01443410.2012.740199

Plomp, T., \& Nieveen, N. (2013). Educational Design Research: An Introduction. (T. Plomp \& N. Nieveen, Eds.), Educational Design Research. Enschede: Netherlands Institute for Curriculum Development (SLO). https://doi.org/10.1007/978-1-4614-31855_11

Putra, M. I. S., Widodo, W., \& Jatmiko, B. (2016). The development of guided inquiry science learning materials to improve science literacy skill of prospective mi teachers. Jurnal Pendidikan IPA Indonesia, 5(1), 83-93. https://doi.org/10.15294/jpii.v5i1.5794

Rodríguez-Ardura, I., \& Meseguer-Artola, A. (2017). Flow in e-learning: What drives it and why it matters. British Journal of Educational Technology, 48(4), 899-915. https://doi.org/10.1111/bjet.12480

Roll, I., Butler, D., Yee, N., Welsh, A., Perez, S., Briseno, A., ... Bonn, D. (2018). Understanding the impact of guiding inquiry: the relationship between directive support, student attributes, and transfer of knowledge, attitudes, and behaviours in inquiry learning. Instructional Science, 46(1), 77-104. https://doi.org/10.1007/s11251-0179437-X 
Santrock, J. W. (2018). Educational psychology: theory and application to fitness and performance (Sixth Edit). New York: McGraw-Hill Education.

Schunk, D. H. (2012). Learning theories: An Educational Perspective (6th ed.). Boston: Pearson Education, Inc. https://doi.org/10.1017/CBO9781107415324.004

Serafin, C. (2016). The Re-conceptualization of Cooperative Learning in an Inquiryoriented Teaching. Procedia - Social and Behavioral Sciences, 217, 201-207. https://doi.org/10.1016/j.sbspro.2016.02.064

Shernoff, D. J., Csikszentmihalyi, M., Schneider, B., \& Shernoff, E. S. (2003). Student engagement in high school classrooms from the perspective of flow theory. School Psychology Quarterly, 18(2), 158-176. https://doi.org/10.1007/978-94-017-9094-9_24

Tlili, A., Essalmi, F., Jemni, M., \& Kinshuk. (2017). Towards Applying Keller's ARCS Model and Learning by doing strategy in Classroom Courses. In Popescu E. et al. (Ed.), Innovations in Smart Learning. Singapore: Springer. https://doi.org/10.1007/978-98110-2419-1

Trnova, E., \& Trna, J. (2015). Motivational Effectiveness of a Scenario in IBSE. Procedia - Social and Behavioral Sciences, 167, 184-189. https://doi.org/10.1016/j.sbspro.2014.12.660

Urbani, J. M., Truesdell, E., Urbani, J. M., Roshandel, S., Michaels, R., \& Truesdell, E. (2017). Developing and Modeling 21st-Century Skills with Preservice Teachers. Collected Faculty and Staff Scholarship, 303.

Wang, P.-H., Wu, P.-L., Yu, K.-W., \& Lin, Y.-X. (2015). Influence of Implementing Inquiry-based Instruction on Science Learning Motivation and Interest: A Perspective of Comparison. Procedia - Social and Behavioral Sciences, 174, 1292-1299. https://doi.org/10.1016/j.sbspro.2015.01.750

Wigfield, A., \& Eccles, J. S. (2000). Expectancy-Value Theory of Achievement Motivation. Contemporary Educational Psychology, 25, 68-81. https://doi.org/10.1006/ceps.1999.1015

Woods-McConney, A., Oliver, M. C., McConney, A., Maor, D., \& Schibeci, R. (2013). Science Engagement and Literacy: A Retrospective Analysis for Indigenous and NonIndigenous Students in Aotearoa New Zealand and Australia. Research in Science Education, 43(1), 233-252. https://doi.org/10.1007/s11165-011-9265-y

Woolfolk, A. (2016). Educational Psychology (13th ed.). London: Pearson Education. 